\title{
Influence of High-Grade Highway Construction on Industry-Economic Belt in Heilongjiang Province
}

\author{
Li Shuxia ${ }^{1}$, Qin Shihuan ${ }^{2}$ \\ ${ }^{1}$ School of Humanities and Social Sciences, Harbin Institute of Technology, Harbin, 150090, China \\ ${ }^{2}$ Shenzhen Graduate school, Harbin Institute of Technology,Shenzhen,518055,China. \\ E-mail:602373072@qq.com
}

Keywords: High-grade Highways; Industry-Economic Belt; "Point-Axis-Facet" Theory; Harbin-Daqing-Qiqihar Industrial Corridor

\begin{abstract}
With the victory of "Three-year decisive battle" of road construction in Heilongjiang Province and the formation of high-grade highway network, high-grade highways gradually have profound effects on promoting economic and social development and enhancing the public life level, as well as meeting the traffic demands in Heilongjiang province. The influence of the highway construction on industrial-economic belt in Heilongjiang province was analyzed. As an example, by forecasting various index of Harbin-Daqing-Qiqihar Industrial Corridor, we confirmed that the construction of high-grade highways in Heilongjiang play positive roles in industrial-economic belt.
\end{abstract}

\section{Introduction}

In the process of building a moderately prosperous society and accelerating modernization, Heilongjiang Province highway transportation needs to achieve leapfrog development in the new environment which is full of great opportunities and severe challenges. In order to promote better and faster development of social economy, the government of Heilongjiang province introduced the Implement compendium of three-year showdown of the highway construction in Heilongjiang Province ${ }^{[1]}$ in August 2008, in which they plan to use more than three years to build freeways of 3042 kilometers and highways of grade 1 or 2 of 3355 kilometers and rural highways of,60,799 kilometers as well as to open up the national and provincial trunk highway, the main highway in the province all the completion of two or more roads. Academia and all levels of government continue to recognize the social and economic benefits of highway and recognition, high-grade highway industry in national economic development strategy, the status of the regional industrial layout and structural adjustment has improved significantly. Therefore, the highway industry-economic belt has gradually become the focus question of the transport of Economic Research.

In our previous evaluation research in high-grade highways ${ }^{[2]}$, high-grade highways in provinces such as Hebei, Hubei, Zhejiang, Anhui,etc,can not only bring good economic benefits, but also contribute more than 3\% on gross domestic product (GDP) of the same period. And the concept of "Industrial economic belt of high-grade highways" was introduced in the General Introduction of Industrial-economic belt of high-grade highways and development along the Yangtze River in Jiangsu Province ${ }^{[3]}$, and its specific function and role profiles of was discussed, and on this basis, a number of targeted recommendations has been made for future development of Industrial-economic belt along the Yangtze River in Jiangsu Province with practice.

For better description of the influence of the construction of high-grade highways on the development of Industrial-economic, we carried on research on four aspects, that is the introduction of the theory, the evolution mode, the "point - axis - side" theory and the contribution of Harbin-Daqing freeway to the Harbin-Daqing-Qiqihar Industrial Corridor. 


\section{High-grade highways industrial-economic belt theory}

High-grade highway industry-economic belt refers to the stripe regional economic system which treat the development of high-grade highway as development spindle and the town or city cluster closely linked to each other on the spindle or in its close attract area (about $50 \sim 80$ kilometers).

And the high-grade highway industry economic belt has the following characteristics ${ }^{[4]}$ : firstly, it's a system of high-capacity, high-speed and high efficiency; Secondly, there exist full-featured towns of various scales in the region; Thirdly, industries in this region are concentrated, the scale of the economy is considerable and the growth speed is great; Fourthly, different towns in the area have different division of labor and the industry have a pattern of diffusion in ladder shape along the highway.

In view of this, and combined with the general characteristics of Traffic Economic Belt, the meaning of the high-grade highways industrial economy should be a stripe regional economic system built on high-grade highways and the transport networks they formed, which is based on the features of high-grade highways, which rely on the large and medium-sized cities along the high-grade highways, which treat the import and export and crossroads of the high-grade as growth poles and treat the high-grade highway network and other linear infrastructure (mainly supporting highways, and other communications lines) as the development axis as well, and which is dominated by the development of efficient agriculture, high-tech industries and tourism, information and other emerging industry-led regional economic sustainable development objectives for the constraints of a ribbon, which is the inevitable product of the industrialized societies and is a contemporary space economy form one of the most typical and most common form.

\section{Formation and evolution mode of high-grade highways industrial-economy belt in Heilongjiang}

The constructions of high-grade highways strike the regional economic system which is at low level balance thus inducing the imbalance of regional development. The gathering effect was enhanced and the economic development was accelerated at the exit or the intersection of high-grade highways while economic developments of many other areas are stagnated due to the negative impact of high-grade highways ${ }^{[5]}$. High-grade highways continue to act on the legions along the highways, the general level of economic development in the region are improved, and the extent of the impact of high-grade highways reached equilibrium. Logistics, people, technology flow and the flow of information in the region exchanged freely, level of economic development in each "point" was significantly higher than adjacent areas, and the structure of the economy as a whole space achieved a high grade of balance, then the economic belt of high-grade highway industry has basically taken shape.

Generally speaking, the formation of highway industry-economic belt goes through three phases with significantly different characteristics; following is the elaboration on the formation of the Harbin-Daqing freeway industry-economic belt.

1) Prototype stage

In the early stage after Harbin-Daqing freeway was built, poor economic development regions away from the exit subject to a greater negative impact which reduce the rate of economic growth. At this stage, the decrease in the number of geographical latent region was taken as the principal thing, the amount of the regions was considerable and started decreasing, growing region began to appear and the number of diffusion regions kept the same.

2) Growth Stage

Since Harbin-Daqing freeway opened to Public, agricultural industry structure of the towns along it has undergone tremendous changes. Efficient agriculture, aging, agriculture, and agricultural production area of specialization has been through great development; internal industry structure of industry and the tertiary industry has increased. The number and the strength of the 
towns were rapidly expanded and enhanced, and population kept gathering to the areas along the freeway, polarization effect was further enhanced, and the core - the edge of the dual space structure has become increasingly evident.

3) Maturation Stage

At this stage, Harbin-Daqing freeway economic belt has been expanded rapidly, economic belt within the urban division of functions and linkages became more explicit, satellite towns of cities kept emerging, and the local section of Megalopolis began to appear, the influence basin of the economic belt received more expansion. The main features of this stage is the appearance of the diffusion region and the disappearance of latent types, as well as the decrease or even the disappearance of the output types, and teemed with a large number of growth types whose rate of increase slows down.

If they continued to developing new development axis after the mature of certain industry-economic belt (such as new high grade highway or high-grade railway), then the formation and development of the industrial-economic belt with a new development axis began with a new round of circulation.

\section{Point, axis, facet of industrial-economy belt of high-grade highways in Heilongjiang Province}

\subsection{The "point" of the High-grade highway}

The so-called point means that any one region is starting with some points on the start, then develop along the axis between each point, and interwoven into the economic network, which is the starting point of a regional development. Economic belt of high-grade highways are mainly divided into two types: one is the existing town, the other is located in the town the highway intersection.

There gradually formed the LongYun, New XiangFang, Ha Dong the SongBei four logistics parks which located separately in the south, east, and north in Harbin. And there formed freight market with integrated logistics center as a platform, exhibition and trade hall, Container Yard and logistics trading sector with Daqing Wanbao petrochemical logistics center as a platform, processing area and storage area in Daqing. While there exit formation of three major logistics markets the Nanyuan Logistics Base, the Beiyuan logistics base, and the North Warehouse Logistics Center.

\subsection{The "axis" of the High-grade highway}

Concentration and diffusion of regional economic activities are not in disorder, it has a trend of longitudinal diffusion along the high-grade highway. Attract and diffusion force along the highway will have an important impact on the economic development. It can be predicted that construction of high-grade highway in the three-year showdown will undoubtedly become the axis of future economic development of Heilongjiang.

The direct distance of axis of high-grade highways to attract logistics facilities in the area is about $10 \mathrm{~km}$. Diffusion distance and the distribution range of Logistics center depends on their own skills and the quality of the existing transportation infrastructure, and the travel time along the axis of the high-grade highways. The results show that the logistics facilities located within $5 \mathrm{~km}$ accounting for $75.5 \%$, and $10 \mathrm{~km}$ or less accounting for $97.1 \%$.

Result of advantages survey in freeway interchange near the entrance location shows that it can be helpful for transportation between the cities (51.2\% of investigators), avoiding traffic jam $(50.9 \%)$, operation of the oversize vehicles $(36.8 \%)$, and convenient joints to the port and airport $(9.9 \%)$.

\subsection{The "facet" of the High-grade highway}

High-grade highway economic industry belt is the result of the point-shaft spread, the result of the development is the expansion of gathering center and increase of extreme center, and the further development at this time can form organically contacted urban agglomeration or metropolitan areas with high grade highways as axises, all sorts of cluster center for support, composed of different levels of transportation network within the given areas. Taking Harbin-Daqing freeway as an example, the industrial economy of Harbin-Daqing highway took Harbin and Daqing as developing 
centers, relying on scale economies in the two core cities, whose development pattern is "points and axises". Cities along the highway such as Zhaodong and Anda developed gradually into organic connection part of Harbin and Daqing.

\section{Contribution of Harbin-Daqing freeway on the Harbin-Daqing-Qiqihar Industrial Corridor}

Construction of Harbin-Daqing-Qiqihar Industrial Corridor project, which is located in the southwest of Heilongjiang Province, began in August 2005.The provincial capital city of Harbin, the oil city of Daqing, heavy equipment, industrial city of Qiqihar and cities along the freeway like Zhao Dong and Anda are included in the Corridor, and the total planned area is $921 \mathrm{~km} 2$, the actual start area was $62.4 \mathrm{~km} 2$ by the end of $2009^{[6]}$. Industries prioritized in the cities along Harbin-Daqing-Qiqihar industrial corridor are shown in the table below.

Table 1 Industries prioritized in the cities along Harbin-Daqing-Qiqihar industrial corridor

\begin{tabular}{c|l}
\hline City & \multicolumn{1}{c}{ Industries prioritized } \\
\hline Harbin & $\begin{array}{l}\text { Focus on the development of high-tech such as the leading automotive, aerospace, } \\
\text { mechanical and electrical industry, pharmaceutical industry, environmental } \\
\text { protection industry, information industry, green food industry and modern } \\
\text { logistics industry. }\end{array}$ \\
\hline Daqing & $\begin{array}{l}\text { Focus on developing alternative industries with high additional value, such as } \\
\text { petrochemical, natural gas chemical industry, and substitute industries like } \\
\text { agricultural and sideline products deep processing, textiles, new materials, } \\
\text { machinery manufacturing, electronic information,etc. }\end{array}$ \\
\hline Qiqihar & $\begin{array}{l}\text { Focus on making the equipment industry, expanding the green food industry and } \\
\text { kerosene chemical industry bigger and stronger, developing the electronic } \\
\text { information, environmental protection, energy, paper, metallurgy, building } \\
\text { materials industry vigorously. }\end{array}$ \\
\hline Zhaodong & $\begin{array}{l}\text { Focus on the development of the biotechnology industry and agricultural } \\
\text { products, grain deep-based Chinese herbal medicine deep processing industry. }\end{array}$ \\
\hline Anda & $\begin{array}{l}\text { Focus on the development of dairy-based agricultural and sideline products and } \\
\text { fine chemicals and taking on the petroleum products processing industry under the } \\
\text { radiation of Daqing. }\end{array}$ \\
\hline
\end{tabular}

It can be seen from Table 1, the development of the industry in the cities along the Harbin-Daqing-Qiqihar Industrial Corridor are inseparable from the fast and efficient support of the Harbin-Daqing freeway, it can be concluded that Harbin-Daqing freeway provides a strong support for development of the cities along it. What can be specifically reflected is that it promotes the economic development of the Harbin-Daqing-Qiqihar Industrial Corridor; the social development of the cities in the area of Harbin-Daqing-Qiqihar Industrial Corridor; and the commodity circulation of the Harbin-Daqing-Qiqihar Industrial Corridor; as well as the development of tourism resources along it.

\subsection{Promotion of Harbin-Daqing freeway on the economic development of the Harbin-Daqing-Qiqihar Industrial Corridor}

Harbin-Daqing freeway provides a good investment environment for Harbin-Daqing-Qiqihar Industrial Corridor; promotes the vigorous development of the export-oriented economy of the Harbin-Daqing-Qiqihar Industrial Corridor and the rapid development of utilization of foreign captivate in the region. Changes of gross industrial production from 2006 to2010 along Harbin-Daqing-Qiqihar Industry Corridor and in the project area are shown in Figure 1. 


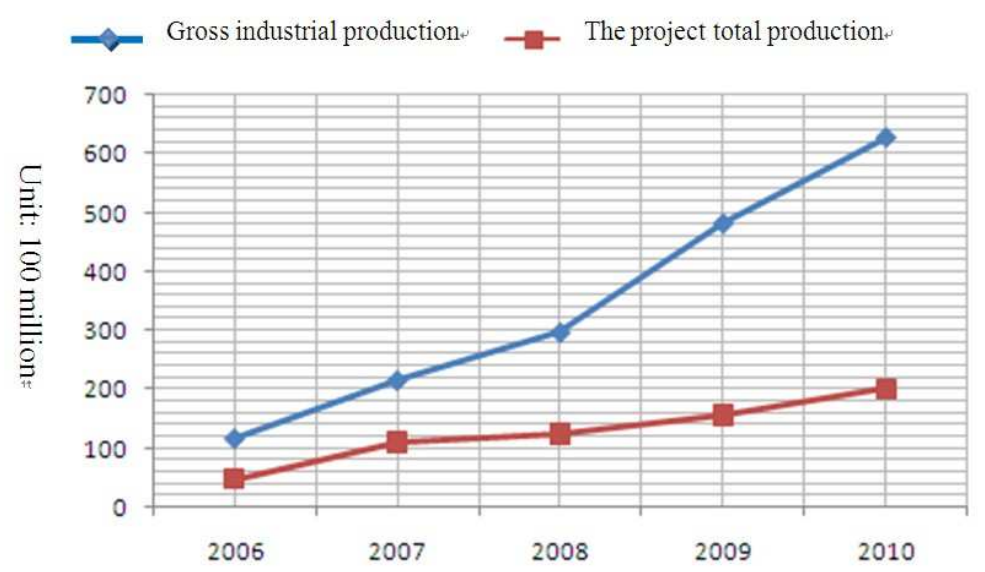

Figure 1 Changes of gross industrial production along Harbin-Daqing-Qiqihar Industry Corridor and in the project area

It can be seen from Figure 1, since the construction of Harbin-Daqing-Qiqihar Industry Corridor the number of enterprises relying on convenient transportation conditions provided by Harbin-Daqing freeway increased with continuous expansion of the construction scale. From 2006 to 2010, GDP in the Harbin-Daqing-Qiqihar Industrial Corridor received rapid development, from 11.7 billions in 2006 to 62.67 billion in 2010 .

\subsection{Promotion of Harbin-Daqing freeway on the social development the cities in the area of} Harbin-Daqing-Qiqihar Industrial Corridor

Harbin-Daqing freeway promotes the economic development of Harbin-Daqing-Qiqihar Industrial Corridor as well as the social development of areas along it. The following table shows how the cities along Harbin-Daqing-Qiqihar Industrial Corridor developed in 2010.

Table 2 Development of the cities along the Harbin-Daqing-Qiqihar Industrial Corridor in 2010

\begin{tabular}{c|c|c|c|c}
\hline Item $\backslash$ City & Harbin & Qiqihar & Daqing & $\begin{array}{c}\text { Zhaodong and } \\
\text { Anda }\end{array}$ \\
\hline The total planning area of the project $\left(\mathrm{km}^{2}\right)$ & 287 & 128 & 340.0 & 217 \\
\hline Gross industrial production $(100$ million) & 192.5 & 133.5 & 231.2 & 69.5 \\
\hline Total production of the project (100 million) & 63.3 & 43.9 & 71.7 & 22.2 \\
\hline
\end{tabular}

It can be seen from Table 2, the total planning area of the project in Daqing is the biggest and followed by Harbin and Qiqihar. Industrial output value of Daqing ranges the first, which is 23.12 billion Yuan, followed by Harbin, Qiqihar, Zhaodong and Anda. Since the project is still in the stage of rapid construction and development, it is reasonable to believe that the rapid development of industrial output value of Harbin, Daqing and Qiqihar will continue.

Gross industrial output value of Harbin and Daqing accounted for more than $70 \%$ of the total output value of Harbin-Daqing-Qiqihar Industrial Corridor, thus Harbin and Daqing becoming two key development supporting points of Harbin-Daqing- Qiqihar Industrial Corridor, which play a decisive role in the development of Harbin-Daqing-Qiqihar Industrial Corridor. As it were, development of cities along the Harbin-Daqing freeway leading the development of Harbin-Daqing-Qiqihar Industrial Corridor.

4.3 Promotion of Harbin-Daqing freeway on the circulation of commodities of the Harbin-Daqing-Qiqihar Industrial Corridor

Due to the construction of Harbin-Daqing freeway, time of the goods in transit is shortened; the economical efficiency of transportation increase and the circulation of commodities in Harbin-Daqing-Qiqihar industrial corridor and the development of urban and rural trade are promoted. At present, Harbin-Daqing-Qiqihar Industrial Corridor is relying on the advantages of the highway to speed up the circulation of commodities and develop to a deeper and wider field with the idea of bigger market and bigger circulation. 
The following table shows the proportion of Harbin-Daqing-Qiqihar Industrial Corridor accounted for the province's freight. It can be seen that freight volume of the cities along Harbin-Daqing-Qiqihar industrial corridor accounted for a large proportion of over $30 \%$ of that in Heilongiiang from 2006 to 2009, among which freight volume of Harbin and Daqing contributed $20 \%$ or more.

Table 3 Proportion of freight volume in Harbin-Daqing-Qiqihar industrial corridor in the total freight volume of the province

\begin{tabular}{c|c|c|c}
\hline Years & $\begin{array}{c}\text { total freight } \\
\text { volume(10000 tons) }\end{array}$ & $\begin{array}{c}\text { Contribution rate of } \\
\text { Harbin-Daqing-Qiqihar Industrial } \\
\text { Corridor (\%) }\end{array}$ & $\begin{array}{c}\text { Contribution rate of } \\
\text { Harbin - Daqing (\%) }\end{array}$ \\
\hline 2006 & 48389 & 34.36 & 22.86 \\
\hline 2007 & 51996 & 32.86 & 21.81 \\
\hline 2008 & 35424 & 51.35 & 34.31 \\
\hline 2009 & 36486 & 45.09 & 27.02 \\
\hline
\end{tabular}

Recently, the comprehensive economic strength and quality of Heilongjiang Province kept springing and the economic attractiveness of the surrounding areas is enhanced, thus providing a broader space for the development and expansion of Harbin-Daqing-Qiqihar Industrial Corridor. The total GDP of the cities along Harbin-Daqing-Qiqihar Industrial Corridor has always been in a steady upward trend. The following table shows GDP and the growth of it in Harbin-Daqing-Qiqihar Industrial Corridor from 2003 to 2010.

Table 4 GDP and its growth in Harbin-Daqing-Qiqihar industrial corridor in 2003-2010

\begin{tabular}{c|c|c|c|c|c|c|c|c}
\hline Project & 2003 & 2004 & 2005 & 2006 & 2007 & 2008 & 2009 & 2010 \\
\hline GDP (100 million) & 4057 & 4750 & 5511 & 6216 & 7077 & 7912 & 8885 & 9996 \\
\hline Growth Rate (\%) & 10.2 & 11.7 & 11.6 & 12.0 & 12.1 & 11.8 & 12.3 & 12.5 \\
\hline
\end{tabular}

\subsection{Promotion of Harbin-Daqing freeway on tourism resource development}

There are rich tourism resources along Harbin-Daqing-Qiqihar Industrial Corridor. People's travel speed is speed up, travel time is shortened and the comfortableness, convenience and continuity of the travel are improved because of the freeway. And the development and effective utilization of tourism resources along the Corridor are promoted.

Highway volumes of passenger traffic in Heilongjiang from 2000 to 2010 are shown in Figure 1-2. Domestic tourist arrivals and tourism revenues of Heilongjiang increased year by year from 2005 to 2010. Convenience of Harbin-Daqing freeway greatly promoted the tourism development of the cities along Harbin-Daqing-Qiqihar Industrial Corridor and the growth of tourism income in Heilongjiang.

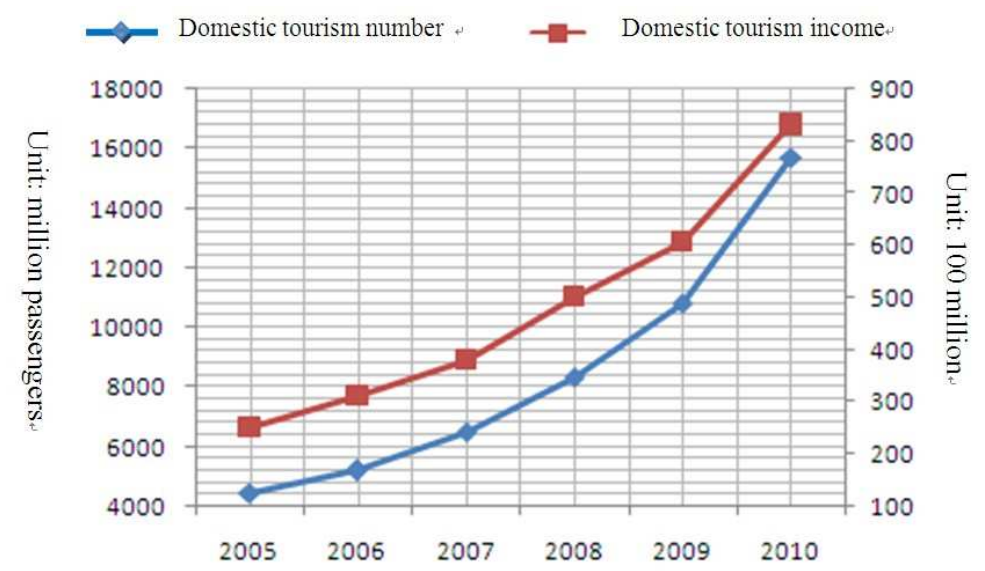

Figure 2 Variation trends of domestic tourist arrivals and tourism revenue in Heilongjiang from 2005 to 2010 


\section{Conclusions}

This article describes the evolution of high-grade highways industrial economic belt, which has gone through three stages of the prototype stage, growth and maturity. Four aspects of contributions of Harbin-Daqing Freeway on the Harbin-Daqing-Qiqihar Industrial Corridor were illustrated, that is the promotion on economic development of Harbin-Daqing-Qiqihar Industrial Corridor, the promotion of social development of the cities along Harbin-Daqing-Qiqihar Industrial Corridor, the promotion on the circulation of commodities of Harbin-Daqing-Qiqihar industrial corridor, and the promotion on the development of tourism resources along it.

\section{References}

[1]Wang Qingyun. Optimize the structure: grasp the adaptability of the transportation and economic development [J]. Integrated transport,2009,(5):20-22.

[2]Shang Jie, Tong Guang Ji.The rapid development of new ways of rural economy [M]. Harbin: Northeast Forestry University Press, 2004, (6)74-83.

[3]Guo Chen, Ming-Hua Yang. Jiangsu Province along the Yangtze River development and the highway industrial economy with Summary [J]. Southeast University of Economics and Management, 2007, (9):05-10.

[4]Nan Liu. The highway's impact on regional economic development --- Zhejiang Province, Hangzhou-Ningbo Expressway [J]. China Soft Science, 2002,(11): 98-101.

[5]HAN Zeng-lin, etc. Highway economic belt formation and evolution mechanism and layout planning method are discussed [J]. Geography, 2001, (4): 471-478.

[6]Harbin-Daqing-Qiqihar Industrial Corridor overall industrial layout planning[R]. Heilongjiang Province Development and Reform Commission, 2005, (8): 11-16.. 